\title{
CeCI n'est PAs un Dessin: Notes on the PROduction and Sharing of FIELDWORK SKETCHES
}

Manuel João Ramos

ISCTE-IUL, Lisbon, Portugal ${ }^{1}$

\begin{abstract}
Whereas the topic of how anthropologists link intimate written information gathered in the field with public production of knowledge in academic formatthe so-called "writing culture" (an expression originated in Clifford and Marcus 1986) -, seems all but exhausted today, little attention has historically been given to the place and goals of sketching as part of that meandering process. The present contribution discusses the ontological and social conditions for the production and reception of knowledge-in-the-field sketches, on drawing as practice and as materiality, and on its bordering with writing.
\end{abstract}

Keywords: graphic anthropology, sketchbooks, non-verbal cognition

Fieldwork notebooks are deemed an indispensable item in the anthropologist's luggage. They are possibly on the way to be replaced by portable computers, digital tablets or smartphones, but I wouldn't be surprised if they were still the typical support for jotting down daily thoughts and memos during ethnographic research missions. Much has been written about the various ways they are used to build up knowledge, i.e. about how "knowledge from the field" is transformed and formatted into "knowledge from the office" (see, for instance, Gomes da Silva 2006). But there seems to be less reflection on the toing and froing that is part of the build-up of anthropological production when the notebook morphs into a sketchbook in the hands of anthropologists more inclined to use graphic means as memorial aids for non-verbal knowledge acquisition. This said, the following remarks aren't meant to offer a straight and clear path into setting out a guidebook-like adoption of rules to put graphic notes and queries into good

1 Centro de Estudos Internacionais, Instituto Universitário de Lisboa. Author's contact: manuel.ramos@ iscte-iul.pt. The present text is partly based on a paper presented at the 2nd edition of the Meeting Nós e os Cadernos, Esposende, 28-30 July 2017, organised by Tiago Cruz and Câmara Municipal de Esposende. 
anthropological use. Building on recent works that highlight the relevance of the topic (Causey 2017; Ingold 2015; Kushnir 2016, among others), they are rather a simple preliminary probe into the conditions for their production and sharing.

In his ironical tale Pierre Ménard, author of Quixote (Borges 2003: 23-40), the Argentinean writer Jorge Luis Borges conceived an effective means of demonstration of the paradoxes of the temporality of written narration that tie together the author and his/her reader. Pierre Ménard, the fictitious French writer born from Borges's pen, devoted himself to the Herculean and heretofore unattempted task of not simply rewriting a whole new Quixote inspired on Cervantes's, but of writing, without changing a single word or comma to the Spanish author's novel, a truer and more original Quixote than the first. Ménard's Quixote, writes Borges, was gloriously freed from the constraints of sense proper to the times in which Cervantes's book was unfortunately trapped. A masterful example of an inverted palimpsest, Ménard's Quixote exposes both the insurmountable contradictions that common sense meets when faced with the disintegrating power of the absurd, and the cyclical, ambiguous and reversible nature of literary production and reception - a nature that's usually obscured by our sieve of beliefs in temporal linearity and semantic literality. Building on the indubitable authority of Master Borges, let us venture into a game of direct analogy and carry the previous reflections into the field of graphic production through notebooks where evocative images of observed moments and spaces are registered, and where concerns of final art clearly give way to the vertigo of the work in progress - I'm here thinking in particular about anthropological fieldwork sketchbooks. Such game of analogy is deemed justifiable by the evidence of the contextual, ontological, and agential contiguity between the act of writing and the act of drawing.

What can, in this respect, the crossing of intertextual analysis with the theory of aesthetic response teach us? At roughly the same time as the provocative Barthesian proposal that the author is dead (Barthes 1984: 61-8) unlocked the flow of research into the palimpsestic transformations of narrative, grammatical and lexical structures that travel from literary text to literary text, a new hermeneutics and phenomenology emerged from the School of Constance, in Germany. Given the premises that in literature "there is no truth outside fiction", Wolfgang Iser, in particular (Iser 1978; 1989), focused much of his analytical endeavour in grasping the aesthetic bonds that tie author and reader together. Since the reader is the one who has to produce sense out of sequences of printed black letters in white sheets (and, by extension, in hexadecimal sets of pixels in luminous, progressively tactile screens) the condition for a successful comprehension of a literary text depends on his/her imaginary adherence to the author's views, ideas and feelings (Iser 1978: 35, 107). Intertextual studies and aesthetic response analyses share the same heuristic intention: that of undoing, if not the foundations at least the frameworks of the classic linear interpretation of the interwoven relations between literary author, work and reader that form and domesticate "common sense". It is fair to presuppose that the production and reception of visual images in sequential format, be it in artbooks, comic books, or graphic notebooks, share a number of interpretative vectors with literary works. As much as we speak of readers' aesthetic responses and of encompassing intertextual networks, there is room to believe that some of the same applies to more graphic and less linguistic-based works. Here, of course, verbalised imagery conveyed through highly standardised typographic 
characters gives way to the non-verbal fluid line, trait, scratch and stain. Still, these resonate with, resemble to, and reinstate, via the viewer's mental imagination, a culture of shared drawn images - or an intergraphical network.

To help make sense of what is implied in this view, let us for a moment examine what happens, not at the reception and response side but at the moment of production of visual images. In a text written in partnership with Brazilian anthropologist Aina Azevedo, we suggested that drawing, at least in its transient sketching or scribbling condition, relates less to the visual arts with reproductive function (photography, film, etc.) than to the act of writing. In other words, we proposed to see cursive writing, first and foremost, as a specialised form of drawing, and to this extent and at that stage, nothing distinguishes a series of letters from a drawing (Azevedo, Ramos 2016: 146). Thus, writing and drawing share the same appeal to the imagination as a productive and communicative source, and a similar attachment to mental sequentiality. Together, they result in an operative distance from the object and make them unlikely, therefore, to claim being proof of objectivity and an instrument of reproducibility of material reality. The trait - or, as anthropologist Tim Ingold has frequently emphasised, the physical impression though which a gesture is materialised (Ingold 2007; 2015) - is the embodied extension and the locus faciendi of the cognitive processes themselves, rather than a simple agential product of confined cerebral structures. Such a view is close to that of the philosophy of mind proposed by Lambros Malafouris (2013: 60), who advocates that the "embodied mind" is the result of a constitutive interpenetration between cognition and material culture, or Andy Clark's converging notion that the "mind is a leaky organ, forever escaping its 'natural' confines and mingling shamelessly with body and with world" "(Clark 1997: 53). By adopting it we may better understand the intricate nature of the multi-dimensional interaction between place perception, optic nerve stimulation, space intellection, memorial recompositing, muscle and tendon activation, object manipulation, gestural fluidity, ocular re-verification, and memorial reinforcement by mirroring reality and the increasing accumulation of gestures.

Drawing is visual music, whose materiality freezes time and flattens space. External stimulation of mental images, signifying meaning without producing a sign, drawing shares a border with writing - a fluid border that is, as we well know, easily and frequently crossed. Even before it gets to reach the gaze of others (i.e., to engender enjoyment and interpretation), the drawing has already become, in an intimate dialogue with the mind-eye-hand that creates it by subverting the normal temporal order. We are in the habit of considering that the drawn image - particularly that which is woven from observation - directly and immediately projects a given reality onto a physical support, and we care little about what goes on between what the eye that sees, the brain that interprets and the hand that performs. Of course, we readily admit the interference of momentary (or enduring) states of mind and of "non-rational" affective conditions in the process of drawing, and we peacefully accept that physical reality itself (let's say, for instance, the vastness of a frozen lake on a cold morning and windy winter morning) can condition or amplify a state of mind (Bourdieu 2000: 272). In this way, we justify a preference for a certain kind of "representation" of reality in lieu of another, based on individual style choices, on the dexterity of the sketcher, and on the cultural habitus that surrounds him/her. But apart from these platitudes, we know very little of what actually goes on, in cognitive terms, during the drawing process, and the peculiar states of (un)consciousness it sparks.

I would like to point out, first of all, that the concept of "representation" fosters so many misunderstandings in the present context that I prefer to refrain from using it at all. 
"Representation" seems an unfortunate and inadequate expression insofar as it depends on a semiotic order that refers us to the field of the linguistic production of meaning. But when trying to understand what constitutes the act of drawing, such field seems as ineffective as using a grammar of the Japanese language to read a dodecaphonic musical score. We are led to do it due to the widespread influence of Saussurean linguistics, which rests much of its epistemological strength on the relation of the representational value of the linguistic sign with a rather enigmatic notion of "mental image." But "mental images" are not, contrary to what the well-known Swiss linguist Ferdinand de Saussure proposed, simple prints of an encyclopaedic catalogue organised by classes and genres to which the mind obediently recurs in order to produce verbal meaning. Mental imagery is whirlwinds, metamorphoses and multidimensions, and even the Piagetian analysis of memorial schemata and the principles of cognitive connectivism falter when circumscribing them.

The complex mental processes involved in the act of drawing are not therefore attempts at reproduction or even at representation of the real. It is even doubtful that the very notion of interpretation may be summoned here with any heuristic value. A drawing does not interpret, as much as it does not reproduce or represent. It is us, babbler beings, who like to think thus - so we can talk about them. But, precisely, drawing does not speak, does not mean, does not reproduce, and does not represent. It should be noted that when I refer generally to "drawing" I am not simply talking about the material outcome separable from the act of its conception and from its remnants in the sketcher's mental memory - drawing is all that at once, without "representing". The drawing of a "horse" on a sheet of paper does not represent a horse, in the linguistic (or theatrical) sense of the term - the "horse" is the name we may, upon wanting to interpret, give to a series of lines or strokes on a physical surface that thus become the external support for a multidimensional mental process. Drawing does not flourish in a univocal manner and does not end its course on the paper that cradles it: the mind that scratches with the hand, stimulated by looking at the world, is itself scratched, carved, impressed. New sensory experiences are thus unconsciously assimilated, and the memories are reworked and reorganised in a cyclical dance between the brain, the gesture and the vision - and looking as gazing around alternates with looking as closely watching the line and the stroke. It is precisely this cyclical and multidimensional nature of the drawing process that attests to its faculty of subverting the linear temporal order. Drawing is not reducible to the automatic act of a robotic machine that, after careful programming (linguistically): 1) "looks" for horse, 2) selects graphic technique, 3) draws "horse". The paper we use may be a tabula rasa, but our mind isn't. Drawing (simultaneously as act and object) is like a revolving door between the world and our mind, where the new and the old, the past and the future, the remembered and the forgotten, pass and meet.

2

The preceding words are far from being a controversial novelty for anyone minimally versed in cognitive psychology. But, in regard to this discipline, let us now borrow from the words of an anthropologist who does not disdain to dialogue with its methods, concerns and points of view. Maurice Bloch (1998: 68-9) notes at one point that:

The problem with psychologists' approach to memory in the real world comes [...] from their failure to grasp the full complexity of the engagement of the mind in culture and history 
and, in particular, their failure to understand that culture and history are not just something created by people but that they are, to a certain extent, that which creates persons.

So far, I have referred to the important fact that, when the sketcher draws, he/she does so primarily for him/herself - because drawing is an act of individual knowledge. But it is not necessary to take it as a merely subsidiary matter that the sketcher draws for others as well because sharing the object "drawing" is a communicational act - and that drawing is not in reality "his/hers" but "ours". This is not the place to carry out a critical reading of the history of Euro-American ideologies which, since the 16th century, fed and excessively amplified the value of the individual creator (the artist), and fabricated the powerful notions of "authorship" and "originality" in a promiscuous partnership with mercantile and financial forces. However, without this caveat on the illusory character of the artist's centrality as the original author in the "great scheme of things" we would have difficulty understanding the ascendancy of collective over individual cognition, and consequently the evidence that each sketcher repeats, in the particular movement of his/her gestures, and in the game of mental recompositing that is his/ her "way of looking at the world", the gestures and schemes proper to the history and culture of the society that made him/her. If for the psychologist (and the art dealer), the sketcher is everything, and for the historian he/she is a link in a narrative chain, for the anthropologist he/ she is no more than a footnote.

It is true that individual memory is shared only partially and fragmentarily, and that drawing is an important factor in the uniqueness of memories forever confined to the sketcher's brain's circumambulations (it lives and dies in him/her: Ramos 2018: 56). We may even say that the material object "drawing" is, in the sketcher's memorial reorganisation process, a "left-over", a disposable excrescence, a by-product of the mental drawing whose sharing offers relatively little to anyone who looks at it. But to dismiss the collective dimension of the production, and reception, of an individual drawing is equivalent to imagining a unicorn forgetting that, apart from the horn, it is a "horse". To better value the time vector in the act of drawing, I hence suggest we accept the working hypothesis that the human mind is eminently social and that there is a risk of absurdity in proceeding atomistically, if we give precedence to the individual cognitive activity and minimise the understanding of its collective nature, as if it was a subsidiary and external element (Hutchins 1995: 364-6). Edmund Leach (1971) contrasted a view that seeks to comprehensively incorporate linear, cyclical and alternate conceptions of the relationship of society with time (1971: 131) to the stubbornly synchronistic model of analysis of social things, which very often anthropologists and sociologists adhere to, or a strictly diachronic (unilinear) historical model. The cumulative effect of such a perspective allows us to advance a way of analysis that we could call multichronic. It is, I think, the one that suits us best to go through the bundles of relations that the sketcher establishes with his/her ("our") creation: a drawing, having happened, cannot be unhappened; but the drawing is not, we have seen, the culmination of a linear process; it comes to be by alternating the gaze and the gesture with the referent, the material object and the mental image; it reorganises a past memory in a cyclical manner; and by recreating the gestures and the traits of the drawings that preceded him, it assumes a palimpsestic nature in the Ménard style.

The notion of intergraphism refers to the various modalities of reference and re-occurrence of traits, frames, textures and motifs that link a drawing to all other drawings produced, and to be produced, in a given historical and cultural context (Azevedo, Ramos 2016: 144). Woven together by the sketcher's creative drive and the aesthetic response of the viewer to the 
drawing, the intergraphic quality of drawings is thus an important pillar of any collective pool of memories and imaginations. In it the literality of meaning explodes, the illusory centrality of the sketcher is dissolved, and temporal linearity becomes distorted, as in a Deleuzian "fold" (fr: pli; Deleuze 1988: 165-6).

3

The following series of sketches I selected from one of my notebooks may be minimally artful and informative as shareable objects. They were made during field research in Northern Ethiopia (with a passage to Lebanon) in 2012, a year when political and religious emotions were running high in the country. I had returned to Gondar (fig. 1), a hitherto sleeping city in the Amhara region that had once been the capital of the ancient Abyssinian kingdom known for its palatial enclosure, a world heritage site. This was a time of great changes: the fast-paced urbanisation the country was (and is) facing impacted all aspects of life in the city. Its demography grew tenfold in ten years, hotels were cropping up everywhere, roads were being speedily carved, and tarmac was spreading over the dusty streets, fuelled by fresh money coming from the diasporas, the international funds and the government. The city of churches, of zar (of Michel Leiris' fame), horse carts and old legends was caving in to Dubai-style buildings, smartphones, tuk-tuks and American-style hamburger-houses (figs. 2, 3, 4 and 9). What my notes and my sketches tried to capture were some of the social and cultural effects of this sudden clash: the spread of extreme poverty (fig. 10 and 11), the heightened religious confrontations (fig. 6), the new exoduses - female migration to Sudan and the Arab countries, male migration to Europe (fig. 14). While a new breed of politician-cum-entrepreneur was taking to the streets and offices of local government (fig. 8), and Muslim youngsters were swapping Sufism for the urban Wahabi culture, I still collected old legends (fig. 5, 7 and 12)- with some new plot twists (fig. 13).

It's a given that my notes and sketches convey little of the conditions, perceptions, emotions, evocations, and thoughts that allowed them to come to being. They are memorial remains of physical appearances (gr. morphé) that can occasionally leap into the sphere of public viewing, while awaiting extinction by the passage of time - which may be smooth and slow as the brittle paper and the chemistry of the inks weather the degradation process, or rapid and drastic if the physics of fire or any other catastrophic occurrence befalls them. They dialogue intermittently with the images (gr. eikón) that flow through neurons and dendrites carried by electrochemical impulses in the unexplorable darkness of the circumambulations of my brain and have become an inalienable part of me, never to be materialised, shown, shared and consumed. By this, I mean that the ontological keys to my physical sketches are the invisible, inviolable and nonshareable mental images that will be one day erased and forever lost upon the event of my brain's death. What others make of them cannot be my business but theirs, and thus I rest my case, as interpretation goes. Nevertheless, it's no less evident that the social and anthropological keys to their apprehension lie in plain sight (pun intended). They are the visual culture I was formed in, the image grammar I learned and manipulate, the aesthetics that frame production and reception, and - last but not least - the insatiable human appetite for partaking graphs. 
Please find the complete photo gallery here:

https://journals.openedition.org/cadernosaa/2425

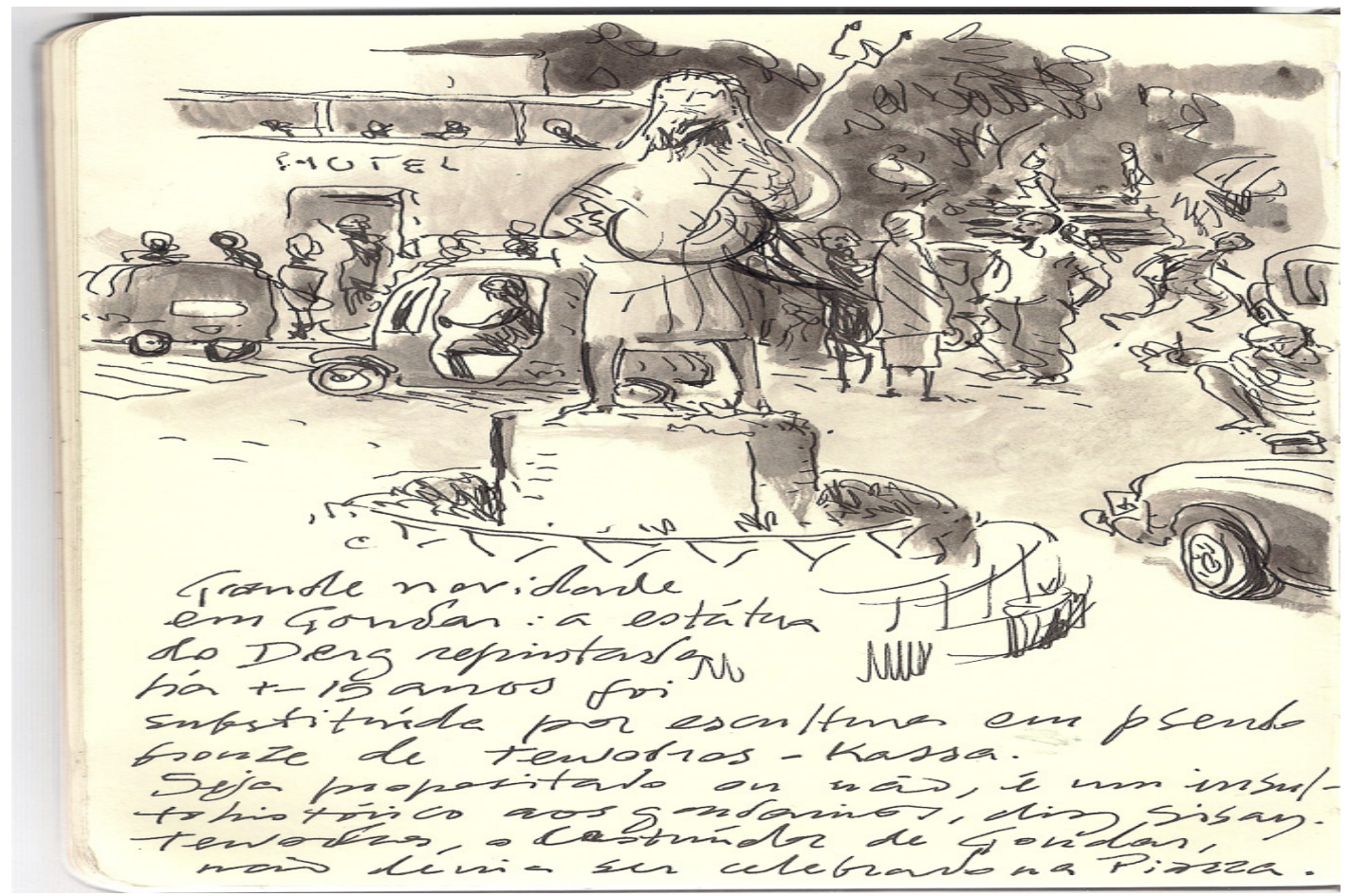

\section{REFERENCES}

Azevedo, Aina, Ramos, Manuel João. 2016. "Drawing Close - On visual engagements in fieldwork, drawing and the Anthropological Imagination”. Visual Ethnography, 5 (1), 135160.

Barthes, Roland. 1984 (1968). "La mort de l'auteur" in Le bruissement de la langue. Essais critiques IV. Paris: Seuil, 61-68.

Bloch, Maurice. 1998. How We Think They Think. Boulder, CO: Westview Press.

Borges, Jorge Luís. 2003 (1944). "Ficções” in Obras Completas I (1923-1949). Lisboa: Teorema, 460-7.

Bourdieu, Pierre. 2000. Esquisse d'une théorie de la pratique. Paris: Seuil.

Clark, Andy. 1997. Being There. Putting Brain, Body, and World Together Again. Cambridge, MA: MIT Press.

Causey, Andrew. 2017. Drawn to See. Drawing as an Ethnographic Method. Toronto: University of Toronto Press.

Clifford, James, Marcus, George (eds.). 1986. Writing Culture. The Poetics and Politics of Ethnography. Berkeley, CA: University of California Press.

Gomes da Silva, José Carlos. 2006. "Objets illusoires de l'écriture”. Revue des Sciences Sociales 36: 14-19.

Deleuze, Gilles. 1988. Le pli. Leibniz et le baroque. Paris: Minuit.

Hutchins, Edwin. 1995. Cognition in the Wild. Cambridge, MA.: MIT Press.

Ingold, Tim. 2007. Lines: A Brief History. London: Routledge. 2015. The Life of Lines. Abington: Routledge. 
Iser, Wolfgang. 1978. The Act of Reading. A Theory of Aesthetic Response. Baltimore: Johns Hopkins University Press.

1989. Prospecting: From Reader Response to Literary Anthropology. Baltimore: Johns Hopkins University Press.

Kuschnir, Karina. 2016 "A antropologia pelo desenho: experiências visuais e etnográficas", Cadernos de Arte e Antropologia, 5, 2: 5-13.

Leach, Edmund. 1971 (1961) "Two essays concerning the symbolic representation of time" in Rethinking Anthropology. London: University of London - The Athlone Press, 124-36.

Malafouris, Lambros. 2013. How Things Shape the Mind. A Theory of Material Engagement. Cambridge, MA: MIT Press.

Ramos, Manuel João. 1997. Ensaios de Mitologia Cristã. As metamorfoses do Preste João. Lisboa: Assírio \& Alvim.

2018. "As imagens e os cadernos" in Tiago Cruz (ed.) Nós e os Cadernos I. Faro: CIAC, Universidade do Algarve, 49-62.

Date received: 2018-12-21

Date accepted: 2019-02-12 